\section{Assessment of Factors Affecting Clinical Practice Competency of Undergraduate Health Science Students in Hawassa University, South, Ethiopia}

\section{Abstract}

Background: Clinical practice experiences are critically important to determine that graduate students are expected to achieve the maximum level of clinical competence after receiving necessary and adequate theoretical and practical instructions. However graduates have problems in doing some easy duties. Thus, this study is designed to assess factors affecting clinical practice competence of undergraduate health science student, Hawassa University, South, Ethiopia, 2015.

Methods: Institutional based Cross-sectional study was conducted in health science students of Hawassa university referral hospital from April to May 2015 by using structured questionnaire and Focus Group Discussion. Simple random sampling was applied to select study subject among 345 students. Data were entered using Epi Info version 3.5.1 was exported and analyzed by SPSS version 20. Bivariate and multivariate logistic regressions were used to identify independent predictors and for qualitative data, ideas were summarized and analyzed in the form of themes.

Result: The prevalence of clinical practice competency from the study participant was $87(25.2 \%)$. Students with adequate clinical case in practical placement were 4 times clinically competent than those students with inadequate clinical case in practical placement with $(\mathrm{AOR}=3.958,95 \% \mathrm{Cl} 1.238,12.65)$. Students with clinical instructor support were clinically competent by 2 times with $(A O R=2.064,95 \% \mathrm{Cl}$ $1.042,3.694)$ than students with no clinical instructor support.

Conclusion and Recommendation: Clinical instructor support, adequate clinical case in practical placement, use continuous assessment checklist and integration of three learning domain were factors affect clinical practice competency of the students.

So improving supervision of clinical instructors, appropriate selection of clinical site and design appropriate clinical practice protocol has important to enhance clinical practice competency of students.

Keywords: Competency, Clinical practice, Clinical practice competency

\section{Rekiku Fikre}

Department of Midwifery, Dilla University, Dilla, Ethiopia

Corresponding author: Rekiku Fikre

\section{”frekiku@yahoo.com}

College of Medicine and Health Sciences, Department of Midwifery, Dilla University, Dilla, Ethiopia

Tel: +251463312097

Citation: Fikre R, Assessment of Factors Affecting Clinical Practice Competency of Undergraduate Health Science Students in Hawassa University, South, Ethiopia. Ann Clin Lab Res. 2016, 4:1.

Received: January 19, 2016, Accepted: January 28, 2016, Published: February 01, 2016

\section{Introduction}

Clinical practice is the means by which student learn to apply the theory facilitating integration of theoretical knowledge and practical skills in the clinical setting which becomes the art and science of the profession. This correlation of theory and practice, and the building of meaningful experience, take place during clinical practice in the health care services [1]. Furthermore, clinical practice is the most important component of health professional education. One of the criteria for effective learning 
in clinical practice is clinical competence. Competencies are the skills, knowledge and attitudes that are instrumental in the delivery of desired results [2].

It is through experience in the clinical setting that students acquires the knowledge, skills, and values essential to professional practice and become socialized into the profession. Clinical experiences are critically important to determine that graduates can become competent professional practitioners after completing their education [3].

Around the world, the rapidly shifting of balance in availability and demands of competent health care workforce, the number of competent health professionals must be expanded to meet these new complexities. The challenges confronting in today's rapidly changing health care environments have highlighted the necessity for graduating students to be both competent and prepared for practice. This necessity has in turn highlighted the increasing significance of the nature and quality of student's clinical learning experience $[4,5]$.

Currently there is great concern from Ethiopian government and the public sector over poor quality of skills of health professionals'. Besides this low client satisfaction was reported in many health facilities and inadequate skill among health professionals was considered as a major factor [6]. Health systems cannot function effectively without sufficient numbers of skilled, motivated and supported health workers who display a good work ethics at all times. However the results of previous study suggested that most new bachelor graduates have adequate theoretical knowledge but lack competence in the clinical environment $[7,8]$.

A lot of questions occur about why this situation exists. Therefore, the purpose of this study is to asses' factors affecting clinical practice competency of undergraduate health science students of Hawassa University referral hospital, south, Ethiopia.

\section{Methods and Materials}

\section{Study area and period}

Hawassa University, previously known as Debub University, was established in April 2000 by merging three colleges, namely Hawassa College of Agriculture, Wondo Genet College of Forestry and Natural Resources, and Dilla College of Teachers Education and Health Sciences. Hawassa city lies $275 \mathrm{Km}$ South of Addis Ababa the capital city of Ethiopia. The altitude of Hawassa is $1665 \mathrm{~m}$ above sea level; now it is the capital city of the South Nation and Nationalities Peoples Region (SNNPR). It has a population of more than 150,000 , from more than 50 different ethnic groups. The University has 64 first degree programs, 43 second degree programs, and $4 \mathrm{PhD}$ programs and has more than 38,000 alumni.

In the medical and health Science College there are 1712 regular and extension students and around 400 academic and administrative staff at different academic levels, ranging from professors, assistant professors and lecturers to graduate assistants. This study was conducted from April to May 2015.

\section{Study population}

All Bsc nurses, Bsc midwifes and Public Health officers studying in nursing, midwifery and public health officer department of Hawassa university health science collage who fulfill the inclusion and exclusion criteria during the study period.

\section{Inclusive criteria}

Bsc nurses, Bsc midwifes and Public Health officers who are involved in more than one clinical practice experience, regular as well and willing to participate in the study.

\section{Exclusive criteria}

- Weekend and extension program Bsc nurses, Bsc midwifes and Public Health officers

- Students with only one clinical experience

\section{Operational definition}

Competency: are once ability of the student to integrate the skills, knowledge and attitudes during in clinical practice.

Learning domain: This is the combination of knowledge, skill and attitude.

Clinical practice: is the means by which students learn to apply the theoretical knowledge in to practical skills in clinical setting.

Clinical practice competency: Are those students who are agreed to the entire six clinical practice assessment questioners.

\section{Study Design and Sample Size Determi- nation}

Institution based cross sectional quantitative study was employed. Sample size was determined using single population proportion formula by considering assumptions of proportion using $5 \%$ as prevalence. $10 \%$ for non-response rate, a total of 345 students were required for the study.

\section{Proportion calculation formula}

$\mathrm{n}=\frac{\mathrm{z}^{2} \alpha / 2 \mathrm{p}(1-\mathrm{p})}{\mathrm{d}^{2}}$

Where,

$\mathbf{n}=$ minimum sample size required for the study

$Z \alpha / 2=1.96$, standardized normal distribution curve value for the $95 \%$ confidence Interval

$\mathbf{p}=0.5$ (in the absence of a similar previous study and to achieve the maximum possible sample size, the following assumption.

$\mathbf{d}=0.05$ degree of margin of error

\section{Sampling procedure}

Simple random sampling was used for the selection of sampling units. Out of 5 campuses of Hawassa University, medical and health Science College were selected purposively. In the next step out of five schools from the selected college two schools was selected randomly which is school of nursing and midwifery and school of public health. Three departments were selected from two schools. Then, the total sample size was allocated to each 
department by stratified proportionate to the number of male and female students per department.

\section{Data collection}

The quantitative data was collected by self-administered questionnaire prepared in English and The questioner contains three parts and 29 closed ended items in four sub-scale which is clinical instructor factor 14 items, clinical environment 6 items, assessment methods 6 items and staff-student interaction 3 items. Qualitative data was collected through Focus Group Discussion by forming four groups and each group contains eight members. The questionnaire was developed based on reviewing different literatures.

\section{Data quality control}

The questionnaires were pre tested and Data collectors were trained for two day on the objectives of the study, sampling procedure, checking the completeness of questionnaires. Furthermore data were checked during entry into the computer before analysis.

\section{Data analysis}

Data were entered using Epi Info version 3.5.1 and entered into computer using SPSS 20 version for analysis. The univariate analysis such as percentage and frequency distribution of different characteristics of the questionnaire was analyzed. Bivariate analysis was used to see the association of independent with the dependent variable. Logistic regression model were employed to control confounding variables; variables included in the model were restricted to those significant $(p=0.05)$ related to clinical practice at the bivariate level and some of the statistical test like, odds 'ratio (crude and adjusted) were used to measure their association and some of the results were compared with results of other studies available. For qualitative data Focus Group Discussion were used and ideas that affect repeatedly were summarized and analyzed in the form of themes.

\section{Ethical consideration}

Paper of approval and letter of permission was obtained before the beginning of data collection from departmental review board of Nursing and Midwifery, College of Health Science, Addis Ababa University. Permission letter were provided to selected collages for proceeding data collection. It is also cleared that participation fully based on the willingness of participants using written consent.

\section{Results}

\section{Socio-demographic characteristics of the study participant}

A total of 345 students were participated in this study with a response rate of $100 \%$. Out of 345 respondents, the sex distribution was $144(41.7 \%)$ were females and $201(58.3 \%)$ were males. Ten (2.9\%) of the respondents were in the age range of between $15-$ 19 years, $320(92.8 \%)$ were in $20-24$ years and $15(4.3 \%)$ were in 25-29 years. About marital status three hundred twelve (90.4\%) of the respondents were single, 33(9.6\%) were married. Most of the participants $234(67.8 \%)$ were orthodox Christian while $22 \%$ and $3.7 \%$ of the respondents were protestant Christian and Muslim respectively and the remaining were others (Table 1). Among the respondent $149(43.2 \%)$ of the study population were Amhara, $111(32.2 \%)$ were Oromo, 35(10.1\%) were Tigray, 21 (6.1\%) were Sidama by ethnicity and $29(8.4 \%)$ were other. Regarding educational status of study participant family, $93(27 \%)$ of respondents were illiterates, 167 (39.7) were certificate, 115 (33.3\%) were diploma and above. About 339(98.3\%) were not use any substance, whereas $6(1.7 \%)$ of the respondent use substance (Table 1).

\section{Prevalence of clinical practice competency of study participants}

The prevalence of clinical practice competency from study participant 87 (25.2\%) were competent over clinical practice

Table 1 Socio demographic characteristics of the study participant in medical and health science college of Hawassa University, Hawassa, Ethiopia ( $\mathrm{N}=345)$.

\begin{tabular}{|c|c|c|c|}
\hline \multicolumn{2}{|c|}{$\begin{array}{c}\text { Variables } \\
\text { Characteristics }\end{array}$} & \multirow{2}{*}{$\begin{array}{l}\text { Frequency } \\
\qquad 144\end{array}$} & \multirow{2}{*}{$\begin{array}{c}\text { Percentage } \\
\text { (\%) } \\
41.7\end{array}$} \\
\hline Sex & Female & & \\
\hline & Male & 201 & 58.3 \\
\hline & Total & 345 & 100 \\
\hline \multirow[t]{4}{*}{ Age } & $15-19$ & 10 & 2.9 \\
\hline & $20-24$ & 320 & 92.8 \\
\hline & $25-29$ & 15 & 4.3 \\
\hline & Total & 345 & 100 \\
\hline \multirow[t]{3}{*}{ Marital status } & Single & 312 & 90.4 \\
\hline & Married & 33 & 9.6 \\
\hline & Total & 345 & 100 \\
\hline \multirow[t]{5}{*}{ Religion } & Orthodox & 234 & 67.8 \\
\hline & Protestant & 76 & 22 \\
\hline & Muslim & 13 & 3.7 \\
\hline & Other & 35 & 10.1 \\
\hline & Total & 345 & 100 \\
\hline \multirow[t]{4}{*}{ Year of study } & $2^{\text {nd }}$ year & 63 & 18.3 \\
\hline & $3^{\text {rd }}$ year & 169 & 40.3 \\
\hline & $4^{\text {th }}$ year & 143 & 41.4 \\
\hline & Total & 345 & 100 \\
\hline \multirow[t]{4}{*}{$\begin{array}{c}\text { Educational status of } \\
\text { family }\end{array}$} & Illiterate & 93 & 27 \\
\hline & Certificate & 137 & 39.7 \\
\hline & $\begin{array}{l}\text { Higher } \\
\text { education }\end{array}$ & 115 & 33.3 \\
\hline & Total & & 100 \\
\hline \multirow[t]{4}{*}{ Residence } & Dormitory & 304 & 88.1 \\
\hline & Rental & 23 & 6.7 \\
\hline & Other & 18 & 5.2 \\
\hline & Total & 345 & 100 \\
\hline \multirow[t]{3}{*}{ Substance use } & Yes & 6 & 1.7 \\
\hline & No & 339 & 98.3 \\
\hline & Total & 345 & 100 \\
\hline \multirow[t]{4}{*}{ Department } & Nursing & 121 & 35.1 \\
\hline & Midwifery & 98 & 28.4 \\
\hline & Health officer & 126 & 36.5 \\
\hline & Total & 345 & 100 \\
\hline
\end{tabular}


whereas 258 (74.8\%) were not competent over clinical practice. There was 114 midwifery student who participate in the study and $26(22.8 \%)$ were competent and 88 (77.1\%) were not competent over clinical practice.

115 health officer were involved and 34 (29.5\%) were competent and 81 (70.4\%) were not competent over clinical practice. From study participant 116 (33.6\%) were nurse student, 27 (23.2\%) were competent clinically and 89 (76.7\%) were not competent over clinical practice (Table 2).

Table 2 The Prevalence of clinical practice competency of study participant by department in medical and health science collage of Hawassa University, Hawassa, Ethiopia.

\begin{tabular}{|c|c|c|c|}
\hline Department & $\begin{array}{c}\text { Number of } \\
\text { student }\end{array}$ & $\begin{array}{c}\text { Not clinically } \\
\text { competent [\%] }\end{array}$ & $\begin{array}{c}\text { Clinically } \\
\text { Competent } \\
{[\%]}\end{array}$ \\
\hline Midwifery & 114 & 77.1 & 22.9 \\
\hline Nursing & 116 & 74.7 & 25.3 \\
\hline Public health officer & 115 & 70.4 & 29.6 \\
\hline
\end{tabular}

\section{Clinical instructor factors response of study participants}

The range of the rating scales were strongly agree $=5$, Agree $=4$, Neutral $=3$, Disagree $=2$ and strongly disagree $=1$. For the purpose of analysis, the above 5 rank responses of closed ended questionnaires were grouped and labeled in to three categories i.e. agree, Neutral and disagree. In categorizing the rating scales, the frequency and percentage results of Strongly agree 'and = agree 'were combined in to _Agree 'and the results of _strongly disagree 'and $=$ Disagree 'merged to Disagree'. Among the respondent the majority $153(44.3 \%)$ were disagree, $95(27.7 \%)$ were strongly disagree, 52(15.1\%) were neutral, 42(12.2\%) were agree and $3(0.9 \%)$ were strongly agree about clinical instructor provides clinical logbook for topics related about clinical practice. About $153(44.3 \%)$ of the respondent were disagree about instructor orientation towards clinical practice, $65(18.8 \%)$ were strongly disagree, 57(16.5\%), were neutral, 46(13.3\%) were agree and $24(7 \%)$ were strongly agree. Most of the respondent 149(43.2\%) were disagree about instructor spent enough time for mentoring during clinical practice, $83(24.1 \%)$ were strongly disagree, 66(19.1\%) were neutral, 40(11.6\%) were agree and $7(2 \%)$ were strongly agree (Table 3$)$.

\section{Clinical practice environment factors response of study participants}

Majority of the respondent $98(28.4 \%)$ were disagree, $57(16.5 \%)$ were strongly disagree, $91(26.4 \%)$ were neutral, $85(24.6 \%)$ were agree and $14(4.1 \%)$ were strongly agree on clinical placement has conducive for clinical practice. About 111(32.2\%) were disagree, 69(20\%) were strongly disagree, 69(20\%) were neutral, $76(22 \%)$ were agree and $20(5.8 \%)$ were strongly agree on clinical placement has sufficient cases for clinical practice (Table 4).

\section{Assessment method factors response of study participants}

About 152(44.1\%) were disagree, 32(9.3\%) were strongly disagree,
75(21.7\%) were neutral, 63(18.3\%) were agree and $23(6.7 \%)$ were strongly agree on instructor orients about assessment methods during clinical practice. Among the respondent $70(20.3 \%)$ were disagree, $10(2.9 \%)$ were strongly disagree, $75(21.7 \%)$ were neutral, $159(46.1 \%)$ were agree and $31(9 \%)$ were strongly agree on assessment methods during clinical practice influence on clinical practice competency. Regarding instructor uses continuous assessment during clinical practice, 155(44.9\%) were disagree, $73(21.2 \%)$ were strongly disagree, 55(15.9\%) were neutral, $45(13 \%)$ were agree and $17(4.9 \%)$ were strongly agree on (Table 5).

\section{Staff-student interaction factors response of study participants}

About majority of the respondent, 109(31.6\%) were strongly disagree, $88(25.5 \%)$ were disagree, $48(13.9 \%)$ were neutral, $92(26.7 \%)$ were agree and $8(2.3 \%)$ were strongly agree on staff allow student to perform some task during clinical practice. Among the respondent, $87(25.2 \%)$ were disagree, 91(26.4\%) were strongly disagree, 43(12.5\%) were neutral, $108(31.3 \%)$ were agree and $16(4.6 \%)$ were strongly agree on staff encourage student during clinical practice.

Regarding staff monitor student during clinical practice, $113(32.8 \%)$ were disagree, $89(25.8 \%)$ were strongly disagree, $51(14.8 \%)$ were neutral, $76(22 \%)$ were agree and $16(4.6 \%)$ were strongly agree on it (Tables 6 and 7).

Multiple logistic regression analysis of independent variable showed that, Students with clinical instructor support has 2 times with $(A O R=2.062,95 \% \mathrm{Cl} 1.042,3.694)$ clinically competent than those students with no clinical instructor support, student with adequate clinical case in clinical placement has 4 times (AOR=3.958, 95\% Cl 1.238, 12.65) clinically competent than those students with few clinical case in clinical placement (Tables 8 and 9).

\section{Focus group discussion}

A total of 32 participants were involved in four groups of Bsc Nursing, Bsc Midwifery, and Public health officer student. Ten specific research questions were prepared under five major headings. Most of the participant agrees that majority clinical supervision were not enough to support their clinical practice competency so that their competency was highly influenced. One of the discussants said," Majority of the student believed that availability of clinical supervisor is useless, supervisor doesn't add any value for our clinical rather than checking our presence in practice site." Similarly, another student expressed that, "clinical supervisor in general have less ability to interact with staffs and they lack confidence to do certain procedure in front of the staff and student".

The group discussants were asked about assessment method fairness. The majority of the discussants reflected mixing of feeling with no clear choice about its fairness.

Some of the discussants agreed that the assessment methods were fair. However, one of the discussant stated that, "if you have good theoretical knowledge you will score better score instead of your clinical skill and continuous mentoring which is totally unfair."

Similarly, another student mentions that," if you have good communication with your instructor you will score high, so which is not fair." 
Table 3 Clinical instructor factors response of study participant in medical and health science collage of Hawassa University, Hawassa, Ethiopia.

\begin{tabular}{|c|c|c|c|c|c|c|c|c|c|c|c|}
\hline \multicolumn{2}{|r|}{ Clinical instructor Factors } & \multicolumn{2}{|c|}{ Strongly agree } & \multicolumn{2}{|c|}{ Agree } & \multicolumn{2}{|c|}{ Neutral } & \multicolumn{2}{|c|}{ Disagree } & \multicolumn{2}{|c|}{ Strongly disagree } \\
\hline & & No. & $\%$ & No. & $\%$ & No. & $\%$ & No. & $\%$ & No. & $\%$ \\
\hline 1 & Provide logbook & 3 & 0.9 & 42 & 12.2 & 52 & 15.1 & 153 & 44.3 & 95 & 27.5 \\
\hline 2 & Orient objective of clinical practice & 24 & 7 & 46 & 13.3 & 57 & 16.5 & 153 & 44.3 & 65 & 18.8 \\
\hline 3 & Spent enough time on clinical site & 7 & 2 & 40 & 11.6 & 66 & 19.1 & 149 & 43.2 & 83 & 24.1 \\
\hline 4 & continuously follow students during practice & 9 & 2.6 & 44 & 12.8 & 75 & 21.7 & 138 & 40 & 79 & 22.9 \\
\hline 5 & Use $d / t$ learning methods & 6 & 1.7 & 64 & 18.6 & 71 & 20.6 & 125 & 36.2 & 79 & 22.9 \\
\hline 6 & Integrate theory in treatment plan & 14 & 4.1 & 43 & 12.5 & 65 & 18.5 & 151 & 43.8 & 72 & 20.9 \\
\hline 7 & Demonstrate skill during practice & 11 & 3.2 & 45 & 13 & 61 & 17.7 & 149 & 43.2 & 79 & 22.9 \\
\hline 8 & Facilitate inter-professional relationship & 9 & 2.6 & 48 & 13.9 & 74 & 21.4 & 132 & 38.3 & 82 & 23.8 \\
\hline 9 & Maintain professional relationship with student & 12 & 3.5 & 42 & 12.2 & 73 & 21.2 & 156 & 45.2 & 62 & 18 \\
\hline 10 & Follow while student conduct procedure & 10 & 2.9 & 48 & 13.9 & 57 & 16.5 & 156 & 45.2 & 74 & 21.4 \\
\hline 11 & Show clinical procedure & 10 & 2.9 & 46 & 13.3 & 45 & 13 & 170 & 49.3 & 74 & 21.4 \\
\hline 12 & Provides constructive feedback & 6 & 1.7 & 47 & 13.6 & 90 & 26.1 & 118 & 34.2 & 84 & 24.3 \\
\hline 13 & Feedback influence clinical practice Competency & 20 & 5.8 & 209 & 60.6 & 38 & 11 & 43 & 12.5 & 35 & 10.1 \\
\hline 14 & Support influence clinical practice & 37 & 10.7 & 153 & 44.3 & 52 & 15.1 & 70 & 20.3 & 33 & 9.6 \\
\hline
\end{tabular}

Table 4 Clinical practice environmental factors response of study participant in medical and health science collage of Hawassa University, Hawassa, Ethiopia.

\begin{tabular}{|c|c|c|c|c|c|c|c|c|c|c|c|}
\hline & \multirow{2}{*}{ Clinical practice environmental factors } & \multicolumn{2}{|c|}{ Strongly agree } & \multicolumn{2}{|c|}{ Agree } & \multicolumn{2}{|c|}{ Neutral } & \multicolumn{2}{|c|}{ Disagree } & \multicolumn{2}{|c|}{ Strongly disagree } \\
\hline & & No. & $\%$ & No. & $\%$ & No. & $\%$ & No. & $\%$ & No. & $\%$ \\
\hline 1 & Clinical practice environment are conducive & 14 & 4.1 & 85 & 24.6 & 91 & 26.4 & 98 & 28.4 & 57 & 16.5 \\
\hline 2 & Clinical practice environment has sufficient cases & 20 & 5.8 & 76 & 22 & 69 & 20 & 111 & 32.2 & 69 & 20 \\
\hline 3 & Clinical practice environment has sufficient material & 16 & 4.6 & 87 & 25.2 & 77 & 22.3 & 108 & 31.3 & 57 & 16.5 \\
\hline 4 & $\begin{array}{l}\text { Clinical practice environment has meet objectives } \\
\text { of clinical .practice }\end{array}$ & 13 & 3.8 & 41 & 11.9 & 84 & 24.3 & 159 & 46.1 & 48 & 13.9 \\
\hline 5 & Clinical practice environment has sufficient ward & 23 & 6.7 & 95 & 27.5 & 78 & 22.6 & 99 & 28.7 & 50 & 14.5 \\
\hline 6 & influenced by clinical environment & 111 & 32.2 & 164 & 47.5 & 29 & 8.4 & 34 & 9.9 & 7 & 2 \\
\hline
\end{tabular}

Table 5 Assessment method factors response of study participant in medical and health science collage of Hawassa University, Hawassa, Ethiopia.

\begin{tabular}{|c|c|c|c|c|c|c|c|c|c|c|c|}
\hline & \multirow{2}{*}{ Assessment factors } & \multicolumn{2}{|c|}{ Strongly agree } & \multicolumn{2}{|c|}{ Agree } & \multicolumn{2}{|c|}{ Neutral } & \multicolumn{2}{|c|}{ Disagree } & \multicolumn{2}{|c|}{ Strongly disagre€ } \\
\hline & & No. & $\%$ & No. & $\%$ & No. & $\%$ & No & $\%$ & No. & $\%$ \\
\hline 1 & $\begin{array}{l}\text { Instructor orient about assessment } \\
\text { methods }\end{array}$ & 23 & 6.7 & 63 & 18.3 & 75 & 21.7 & 152 & 44.1 & 32 & 9.3 \\
\hline 2 & $\begin{array}{l}\text { Influence of assessment methods on } \\
\text { clinical Practice }\end{array}$ & 31 & 9 & 159 & 46.1 & 75 & 21.7 & 70 & 20.3 & 10 & 2.9 \\
\hline 3 & $\begin{array}{l}\text { Instructor use continuous assessment } \\
\text { methods }\end{array}$ & 17 & 4.9 & 45 & 13 & 55 & 15.9 & 155 & 44.9 & 73 & 21.2 \\
\hline 4 & Instructor made difference in assessment & 9 & 2.6 & 98 & 28.4 & 83 & 24.1 & 106 & 30.7 & 93 & 14.2 \\
\hline 5 & $\begin{array}{l}\text { Assessment methods address three } \\
\text { learning methods }\end{array}$ & 5 & 1.4 & 29 & 8.4 & 46 & 13.3 & 151 & 43.8 & 141 & 33 \\
\hline 6 & Instructor use checklist & 4 & 1.2 & 22 & 6.4 & 34 & 9.9 & 112 & 32.5 & 173 & 58.1 \\
\hline
\end{tabular}

Table 6 Staff-student interaction factor response of study participant in medical and health science collage of Hawassa University, Hawassa, Ethiopia.

\begin{tabular}{|c|c|c|c|c|c|c|c|c|c|c|c|}
\hline & \multirow{2}{*}{ Staff-student factors } & \multicolumn{2}{|c|}{ Strongly agree } & \multicolumn{2}{|c|}{ Agree } & \multicolumn{2}{|c|}{ Neutral } & \multicolumn{2}{|c|}{ Disagree } & \multicolumn{2}{|c|}{ Strongly disagree } \\
\hline & & No. & $\%$ & No. & $\%$ & No. & $\%$ & No. & $\%$ & No. & $\%$ \\
\hline 1 & $\begin{array}{l}\text { Staff allow student to perform task during } \\
\text { clinical practice }\end{array}$ & 8 & 2.3 & 92 & 26.7 & 48 & 13.9 & 88 & 25.5 & 109 & 31.6 \\
\hline 2 & $\begin{array}{l}\text { Staff encourage students during clinical } \\
\text { practice }\end{array}$ & 16 & 4.6 & 108 & 31.3 & 43 & 12.5 & 87 & 25.2 & 91 & 26.4 \\
\hline 3 & Staff monitor students & 16 & 4.6 & 76 & 22 & 51 & 14.8 & 113 & 32.8 & 89 & 25.8 \\
\hline
\end{tabular}

All discussants agreed that the main reasons for poor clinical practice competency of student were, due to weak supervision of clinical instructor, some of clinical instructors were inadequate clinical experience and work overload of clinical instructor. 
Table 7 The Response of study participant towards the assessment of clinical practice competency in medical and health science collage of Hawassa University, Hawassa, Ethiopia.

\begin{tabular}{|c|c|c|}
\hline $\begin{array}{c}\text { Variable of clinical practice } \\
\text { competency assessment }\end{array}$ & Not done[\%] & Done [\%] \\
\hline $\begin{array}{c}\text { Apply theory to clinical practice } \\
\text { Apply patient dignity, privacy and } \\
\text { confidentiality }\end{array}$ & 65.5 & 34.5 \\
\hline $\begin{array}{c}\text { Apply health safety } \\
\text { Ability to administer medication } \\
\text { safely }\end{array}$ & 36.5 & 63.5 \\
\hline $\begin{array}{c}\text { Ability to emotional, physical and } \\
\text { personal care }\end{array}$ & 32.5 & 28.7 \\
\hline $\begin{array}{c}\text { Ability to apply need of patient by } \\
\text { planning }\end{array}$ & 78 & 67.5 \\
\hline
\end{tabular}

Table 8 Bivariate logistic regression analysis of clinical practice competency factors of study participant in medical and health science collage of Hawassa University, Hawassa, Ethiopia.

\begin{tabular}{|c|c|c|}
\hline Variables & COR(95\% CI) & P-value \\
\hline Integrate theory to clinical practice & $1.683(0.367,1.270)$ & 0.003 \\
\hline Influence of clinical instructor & $2.257(0.160,0.413)$ & 0.000 \\
\hline Support of clinical instructor & $1.598(0.362,1.988)$ & 0.045 \\
\hline Conducive clinical Placement & $1.694(0.412,1.168)$ & 0.016 \\
\hline $\begin{array}{c}\text { Influence of clinical placement } \\
\text { competency }\end{array}$ & $4.170(2.408,7.221)$ & 0.000 \\
\hline Assessment Checklist & $1.509(0.222,1.168)$ & 0.001 \\
\hline Integration of learning domain & $2.713(0.934,7.98)$ & 0.002 \\
\hline $\begin{array}{c}\text { Orientation about objective of } \\
\text { clinical practice }\end{array}$ & $2.646(1.381,4.096)$ & 0.004 \\
\hline Feedback provided by instructor & $1.782(0.484,1.98)$ & 0.013 \\
\hline
\end{tabular}

Table 9 Multiple logistic regression analysis of clinical practice competency factors of study participant in medical and health science collage of Hawassa University, Hawassa, Ethiopia.

\begin{tabular}{|c|c|c|}
\hline Variable & AOR $(95 \% \mathrm{Cl})$ & P-value \\
\hline $\begin{array}{c}\text { Clinical instructor } \\
\text { support }\end{array}$ & $2.062(1.060,3.996)$ & 0.013 \\
\hline $\begin{array}{c}\text { Integration of learning } \\
\text { domain }\end{array}$ & $3.09(1.047,1.803)$ & 0.001 \\
\hline $\begin{array}{c}\text { Use of assessment } \\
\text { checklist }\end{array}$ & $3.95(1.242,12.694)$ & 0.002 \\
\hline Clinical placement & $1.63(1.18,3.073)$ & 0.004 \\
\hline
\end{tabular}

\section{Discussion}

Institutional based cross-sectional study were carried to assess factors affecting clinical practice competency of undergraduate health science student in medical and health science collage of Hawassa University, Hawassa, south region. The prevalence of clinical practice competency in this study was (25.2\%). These findings is lower than study done in Iran [9] indicate overall competency with clinical practice of students was (38.8\%).

Students with clinical instructor support has increase clinical practice competency by 2 times with (AOR=2.064, 95\% $\mathrm{Cl} 1.042$, 3.694) than students with no clinical instructor support.
This is in line with the study done in England [10]. In this study students with integration of three learning domain by clinical instructor has enhanced clinical practice competency by 3 times (AOR=3.09, 95\% Cl 1.048, 1.742) than students with no integration of three learning domain by clinical instructor. This is in line with the study done in Saudi-Arabia [11]. In this study students with adequate clinical case in practice placement has increase clinical practice competency (AOR=1.685, 95\% Cl 1.908, 3.126 ) than students with few clinical case in practice placements. This is in line with the study done in Australia [12]. But which is lower than study done in Norwegian [13]. In this study students with continuous assessment checklist by clinical instructor has increase clinical practice competency by 4 times (AOR=3.958, 95\% $\mathrm{Cl} 1.238,12.65)$ than students which no continuous assessment by their clinical instructor. This is in line with the study done in united-kingdom [14].

\section{Strengths and Limitations of the Study}

In this study, at the design stage and before the implementation of the study well defined inclusion and exclusion criteria were made, data collectors were trained, questionnaires were tested and necessary corrections made, and all of the questions of the quantitative study were closed ended. The study subjects were selected using random sampling techniques, which helps to avoid selection bias.

Qualitative data, the focus group discussions, gave important supplements to elaborate some findings from the quantitative data. Too little literature were available And Shortage of recently conducted studies are some of the limitation.

\section{Conclusion}

Clinical instructor support, clinical site placement, assessment checklist and integration of three learning domain influence clinical practice competency of study participant.

\section{Recommendations}

Improving clinical instructor supervision and designing appropriate clinical practice protocol has to be considered.

\section{Acknowledgment}

Above all I would like to express my gratitude to my Lord- Jesus Christ who carries all my burdens and shepherded me healthy.

My sincere gratitude goes to my advisor assistance Professor Berhane G/kidan for his relentless support and valuable advice in this proposal development from the inception to the final.

I also extend my gratitude to Addis Ababa University, Allied school of health science, and Department of nursing and midwifery for its financial support in the accomplishment of this study. And next, I would like to thank goes to all data collectors, supervisors and study participants whose contribution was vital to go through the data collection work. 


\section{References}

1 Reilly M, Oerman H (2007) Clinical teaching in nursing education. Journal of nursing education 40: 347-353.

2 Benner P, Tanner C, Chesla C (2006) Expertise in Nursing Practice. Caring, Clinical Judgment and Ethics 37-43.

3 (2005) Federal Ministry of Health; Health sector strategic plan. Planning Programming, Addis Ababa 20-30.

4 Martinez J, Martineau T (2001) Rethinking human resources; an agenda for the millennium. Health Policy Plan 13: 345-358.

5 Ghaljie M, Ghalejaei F, Mazlom A (2008) association between competency and patient satisfaction with nursing care; A Journal ashadide behsheti school of nursing and midwifery 18: 12-19.

6 (2000) American Nurses Association (ANA); Continuing Competence: Nursing's Agenda for the $21^{\text {st }}$ Century; Washington, DC: ANA.

7 (1999) Joint Commission on Accreditation of health care Organizations; Comprehensive Accreditation Manual for Hospitals.

8 Chan D (2002) Development of the clinical learning environment inventory; by using the theoretical framework of learning environment studies to assess students' Perceptions of the hospital as a learning environment. Journal of Nursing Education 41: 69-75.

9 Bezuidenhout MC, Koch S, Netshandama VO (1999) The role of the ward manager in creating a conducive clinical learning environment for students 47-53.

10 Connecticut State Board of Education (2001) Position Statement on Student Support Services. Hartford, CT: Connecticut State Board of Education.

11 (2011) Adv in Health Sci Educ; this article is published with open access at Springerlink.com (Saudi arbi) 16: 553-567.

12 Chun-Heung L, French P (2007) Education in the practicum; a study of the ward learning climate in Hong Kong; Journal of Advanced Nursing 26: 455-462.

13 Bell PF, Daly J, Chang EM (1997) A study of the educational and research priorities of registered nurses in rural Australia; Journal of Advanced Nursing 25: 794-800.

14 Neary M (2002) Supporting students' learning and professional development through the process of continuous assessment and mentorship health Education Today 20: 463-474. 